\title{
EFFECT OF SERUM 25(OH) D LEVEL, CIGARETTE SMOKING AND ORAL CONTRACEPTIVE USE ON CLINICAL COURSE OF RELAPSING-REMITTING MULTIPLE SCLEROSIS IN A GROUP OF FEMALE PATIENTS
}

\author{
Molnar Kinga ${ }^{1}$, Rodica Balasa ${ }^{2,3}$ \\ ${ }^{1}$ University of Medicine and Pharmacy, Targu-Mures \\ ${ }^{2}$ University Emergency County Hospital, Targu-Mures \\ ${ }^{3}$ Regional MS Centre, University Emergency County Hospital, Targu-Mures
}

\begin{abstract}
Objective. This study was conducted to analyze the effect of certain environmental factors on clinical and laboratorial variables in a cohort of multiple sclerosis patients.

Material and methods. Serum vitamin $25(\mathrm{OH}) \mathrm{D}$, smoking habits and oral contraceptive use were evaluated in 36 relapsing-remitting MS female patients between ages 29-45 under Interferon beta-1a therapy. Clinical variables included annualized relapse rate and Expanded Disability Status Scale (EDSS). The effect of sun exposure, dietary and smoking habits and oral contraceptive use on $25(\mathrm{OH}) \mathrm{D}$ levels was also examined.

Results. Patients with higher $25(\mathrm{OH}) \mathrm{D}$ serum levels and consumers of oral contraceptives $(\mathrm{OC})$ had better clinical outcomes, but not in a statistically significant extent. The practice of artificial tanning, consumption of alternative sources of vitamin D (cod liver oil, omega-3 fatty acids) and the use of oral contraceptives were associated with significantly higher vitamin D levels.

Conclusions. Smoking seems to have less effect on disease progression and vitamin D levels than anticipated. Oral contraception use could be benefic and maintaining a high plasma D level is also encouraged in MS patients.
\end{abstract}

Keywords: multiple sclerosis, vitamin D, smoking, oral contraceptives

Multiple sclerosis is one of the most frequent causes of disability amongst young adults, affecting mainly the age group of 30 and 40 . The female and male ratio is $3: 2(1)$. It is determined by a combination of genetic and environmental factors, but the precise role of these factors needs to be further elucidated. Out of the genetic risk factors, HLADRB $1 * 1501$ haplotype is the strongest genetic predictor of MS risk (2). The external factors that probably play a role in the etiology of the disease include Ebsein-Barr virus (EBV) infection, cigarette smoking, and suboptimal serum levels of vitamin D (3). Oral contraceptive use does not increase the risk of multiple sclerosis (4). These factors could also be involved in disease activity and progression.

Vitamin D or calciferol can be ingested orally but its main source is the production in the skin following exposure to sunlight. Its serum concentration depends on geographical latitude, season, skin pigmentation, age and it is also influenced by certain factors connected to lifestyle: dietary habits, vitamin supplementation and sun exposure.

Beside its role in modulating calcium homeostasis, vitamin D is well known for its immunomodulatory and anti-inflammatory actions as well (5). There is strong evidence to suggest that it has measurable effect on T-cell reactivity in MS patients, 
mediating a shift of T-cells to an anti-inflammatory profile $(6,7)$. Based on these findings, adequate serum levels of vitamin $\mathrm{D}$ is assumed to have a benefic influence on the course of MS, both on the frequency of relapses and the progress of disability. Several, but not all studies suggest that higher vitamin D metabolite levels are associated with higher chance to remain relapse-free and with lower disability scores (8-11).

Smoking may also exert an influence on the course of MS. Observational studies suggest that smoking facilitates the transformation of clinically isolated syndrome (CIS) to definite disease, and also accelerates the conversion from relapsing-remitting form to a more severe secondary progressive form $(12,13)$. Smoking may also increase disability scores, but no association was found between smoking and relapse rate $(12,13)$. Based on the heterogeneous results of the studies, a trend towards the harmful effect of smoking is observed but it cannot be stated for certain.

The role of OCs in disease progression is not clear, but it may have a benefic effect on the course of the disease by increasing the serum vitamin $\mathrm{D}$ levels $(14,15)$.

The aim of this study is to identify those factors that significantly increase serum vitamin $\mathrm{D}$ concentration, thus indirectly have a benefic effect on MS disease evolution. Furthermore we examine the direct role of serum vitamin D concentration, smoking habits and oral contraceptive use on relapsingremitting MS evolution in terms of annual relapse rate and EDSS score.

\section{SUBJECTS AND METHODS}

36 patients diagnosed with relapsing-remitting multiple sclerosis were included in our study. The including criteria were as follows: female sex, age between 29-45 years, receiving immunomodulatory therapy with Interferon beta-1a of subcutaneous or intramuscular administration in First Neurological Clinic, University Emergency County Hospital, Targu-Mures. One patient did not approve of the venepuncture, in her case we used only anamnestic and clinical data. All participants gave their written informed consent.

Based on anamnestic and laboratorical information, the participants were subdivided into more groups. According to serum 25(OH) D levels there were two groups, one with adequate and another with inadequate serum vitamin $\mathrm{D}$ concentrations. Based on personal smoking history there were a group of smokers (defined by smoking for at least
10 years, at least 10 cigarettes a day) and a group of non-smokers. Similarly, a third subgroup was distinguished based on oral contraceptive use: users were defined as present or past consumers of OC for at least 3 months after the diagnosis of MS or maximum 5 years beforehand. Non-users were those participants that did not fit these criteria. Members of the user subgroup took combination pills with ethinyl estradiol with variable progestin component.

Each subject completed a questionnaire designed to study the intake of vitamin $\mathrm{D}$. The questionnaire is similar to the one used in the study of Bolek-Berquist et al, and consists of questions referring to natural or artificial tanning in the last 12 months, sunscreen use, the average length of sun exposure the previous week, milk consumption, multivitamin or vitamin D supplement consumption and the presence of conditions known to affect vitamin $\mathrm{D}$ absorption (16).

During the study of the effect of smoking and oral contraceptive use on vitamin D concentrations, 8 patients that took oral or intravenous supplementation of calciferol were excluded.

Protocol variables included neurological dysfunction and disability (determined by neurological examination, numerically expressed by EDSS score), duration of disease, number of previous relapses, annualized relapse rate, and serum 25-hydroxi vitamin $\mathrm{D}$ concentrations.

Blood samples were obtained by venepuncture during winter and spring months (from November to May). Serum 25- hydroxi vitamin D levels were determined using chemilumiflourescent assay. Optimal levels were defined by a cut-off of $30 \mu \mathrm{g} / 1$ (approximately $75 \mathrm{nmol} / \mathrm{l}$ ), below this value the results were considered insufficient.

Statistical analysis was performed by student $t$ test, ANOVA test and Pearson correlation coefficient.

\section{RESULTS}

The study population is made up by 36 female patients, diagnosed of relapsing-remitting MS. Serum vitamin $\mathrm{D}$ concentrations were determined in all but one case. The average age is 37 years old, disease duration varies between 1 and 21 years, with a mean of 7.6 years. The mean annualized relapse rate (ARR) is 0.58 , and the mean EDSS score is between 1.0 and 1.5 which indicates no disability and minimal signs in one or more functional systems (17). $88.6 \%$ of the patients had lower serum calciferol concentration that the $30 \mu \mathrm{g} / 1$ cut-off. 
The average $25(\mathrm{OH}) \mathrm{D}$ level is $17.4 \mu \mathrm{g} / \mathrm{l}$, the value of measurements varies between 4.4 and $46.7 \mu \mathrm{g} / 1$. Other clinical characteristics of the participants can be seen in Table 1.

TABLE 1. Characteristics of the study population

\begin{tabular}{|l|c|}
\hline $\mathbf{N}$ & 37 \\
\hline Age (years) & $\begin{array}{c}29-45 \\
\text { mean: } 37\end{array}$ \\
\hline Age at disease offset (years) & $30 \pm 7$ \\
\hline Disease duration (years) & $7.6 \pm 5.3$ \\
\hline ARR* & $0.58 \pm 0.55$ \\
\hline EDSS** & $1.3 \pm 1.6$ \\
\hline Serum 25(OH) D concentration $(\boldsymbol{\mu g} / \mathbf{I})$ & $17.4 \pm 9.5$ \\
\hline Smoking (N,\%) & 14 \\
\hline Oral contraceptive use (N,\%) & $37.8 \%$ \\
\hline Duration of immunomodulatory therapy (years) & 13 \\
\hline $\begin{array}{l}\text { Values are expressed as mean } \pm \text { SD } \\
\text { *Annualized relapse rate } \\
\text { ** Expanded Disability Status Scale }\end{array}$ \\
\hline
\end{tabular}

The questionnaire identified the following characteristics - the number and percentage of the yes answer is shown in brackets: natural tanning in the last 12 months $(\mathrm{N}=12 ; 34.2 \%)$, sunscreen use $(\mathrm{N}=18 ; 51.4 \%)$, average sun exposure the previous week (less than 5 min/day: $\mathrm{N}=19 ; 54.2 \% ; 5-15$ $\mathrm{min} /$ day: $\mathrm{N}=9 ; 25.7 \% ; 15-30 \mathrm{~min} /$ day: $\mathrm{N}=6 ; 17.1 \%$; more than $30 \mathrm{~min} /$ day: $\mathrm{N}=1 ; 2.8 \%$ ), tanning booth use $(\mathrm{N}=4 ; 11.4 \%)$, daily milk consumption $(\mathrm{N}=25$; $71.4 \%)$, multivitamin use ( $\mathrm{N}=9 ; 25.7 \%)$, vitamin $\mathrm{D}$ supplement intake $(\mathrm{N}=8 ; 22,8 \%)$, cod liver oil or omega-3 fatty acid intake $(\mathrm{N}=10 ; 28.5 \%)$. No intestinal or bowel disease was reported. Out of these factors, two were associated with significantly higher serum $25(\mathrm{OH}) \mathrm{D}$ levels: the first is tanning booth use $(26.63 \pm 15.18$ versus $16.2 \pm 8.16$, p-value $=0.04)$, the second is cod liver oil or omega-3 fatty acid intake $(24.8 \pm 8.88$ versus $14.43 \pm 8.16$ $\mathrm{p}$-value $=0.002$ )

Table 2 Summarizes the result of comparing the subgroups mentioned in Subjects and methods section.

As visible, both ARR and EDSS values are higher in suboptimal $25(\mathrm{OH})$ D concentration group, which denotes a more severe disease course, although the difference is not statistically significant. There is no significant difference between the results of smokers in comparison with non-smokers either. Oral contraceptive users' mean ARR and EDSS values are lower, but again, no statistical difference is observed between user and non-user group. The duration of therapy did not correlate

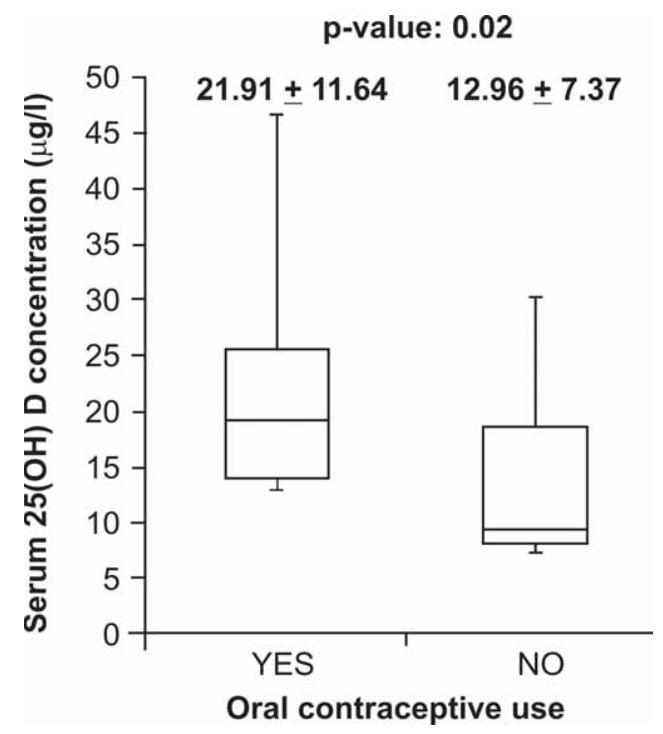

FIGURE 1. Serum vitamin D concentrations of oral contraceptive users and non-users

with ARR (Pearson correlation coefficient, $\mathrm{r}=$ $0.29)$ or with $\operatorname{EDSS}(r=0.13)$.

11 smokers and 16 non-smokers reported no vitamin D supplementation prior to this study. Their vitamin $\mathrm{D}$ levels are not significantly different $(14.5 \pm 7.13 \mu \mathrm{g} / 1$ for smokers, $17.94 \pm 13.51 \mu \mathrm{g} / 1$ for non-smokers, p-value: 0.4$)$. On the other hand, OC users $(\mathrm{N}=9)$ have significantly increased serum $25(\mathrm{OH}) \mathrm{D}$ concentrations compared to non-users $(\mathrm{N}=18): 21.91 \pm 11,64 \mu \mathrm{g} / 1$ versus $12.96 \pm 7.37$ $\mu \mathrm{g} / \mathrm{l}, \mathrm{p}$-value: 0.02 (shown in Figure 1). Moreover, the duration of the intake correlates with the vitamin D level (Pearson correlation coefficient, $\mathrm{r}=$ $\left.0.67, r^{2}=0.45\right)$.

\section{DISCUSSION}

The results of this study demonstrate that the average $25(\mathrm{OH}) \mathrm{D}$ levels amongst relapsing-remitting MS patients are far below optimal level, and only a few ( $\mathrm{N}=4)$ of our subjects had $\geq 30 \mu \mathrm{g} / 1$ serum concentrations. This result not only shows the widespread vitamin D defficiency of MS patients but it raises the issue of serum $25(\mathrm{OH}) \mathrm{D}$ levels considered „normal”. The lower limit of optimal range has been determined as the serum level above whose beneficial skeletal effects of vitamin D can be observed (18). The optimal limit for its immunological effects is not yet unequivocally defined. An observational study with calciferol supplemenation proved beneficial effect of higher serum levels on disease course only below a concentration of 110 nmol/1 (approximately $45 \mu \mathrm{g} / \mathrm{l}$ ) (19). This shows that a higher vitamin $\mathrm{D}$ concentration may be needed for the pozitive extra-skeletal effects. 
In light of these findings it is not suprising that our study proved no direct effect of vitamin D concentration on ARR and EDSS. It has to be mentioned though that lower average relapse rate and EDSS scores were registered in the optimal serum $25(\mathrm{OH}) \mathrm{D}$ concentration group. A possible confusing factor is the fact that our patients were already on immonomodulatory therapy with INF $\beta$, whose immunological effects may have interfered with the effects of vitamin D. For instance, both of these substances increase IL-10 levels (20).

TABLE 2. Variables associated with serum vitamin $D$ concentration, smoking status and oral contraceptive use

\begin{tabular}{|c|c|c|c|}
\hline & $\begin{array}{c}25(\mathrm{OH}) \mathrm{D}<30 \mu \mathrm{g} / \mathrm{I} \\
\mathrm{N}=31^{\mathrm{a}}\end{array}$ & $\begin{array}{c}25(O H) D \geq 30 \mu g / l \\
N=4^{a}\end{array}$ & p-value \\
\hline ARR* & $0.60 \pm 0.56$ & $0.48 \pm 0.52$ & 0.69 \\
\hline \multirow[t]{2}{*}{ EDSS** } & $1.45 \pm 1.76$ & $0.5 \pm 0.58$ & 0.3 \\
\hline & $\begin{array}{c}\text { Smokers } \\
\mathrm{N}=13\end{array}$ & $\begin{array}{c}\text { Non-smokers } \\
\mathrm{N}=23\end{array}$ & p-value \\
\hline ARR* & $0.58 \pm 0.34$ & $0.62 \pm 0.65$ & 0.85 \\
\hline \multirow[t]{2}{*}{ EDSS** } & $1.08 \pm 1.15$ & $1.48 \pm 1.9$ & 0.49 \\
\hline & $\begin{array}{c}\text { Oral contraceptive } \\
\text { users } \\
\mathrm{N}=12 \\
\end{array}$ & $\begin{array}{c}\text { Non-users } \\
N=24\end{array}$ & p-value \\
\hline ARR* & $0.46 \pm 0.36$ & $0.68 \pm 0.62$ & 0.26 \\
\hline EDSS** & $0.7 \pm 1.18$ & $1.6 \pm 1.82$ & 0.17 \\
\hline
\end{tabular}

Values are expressed as mean \pm SD.

*Annualized relapse rate; ** Expanded Disability Status Scale

${ }^{\text {a }}$ The total number of vitamin D samples obtained is 35

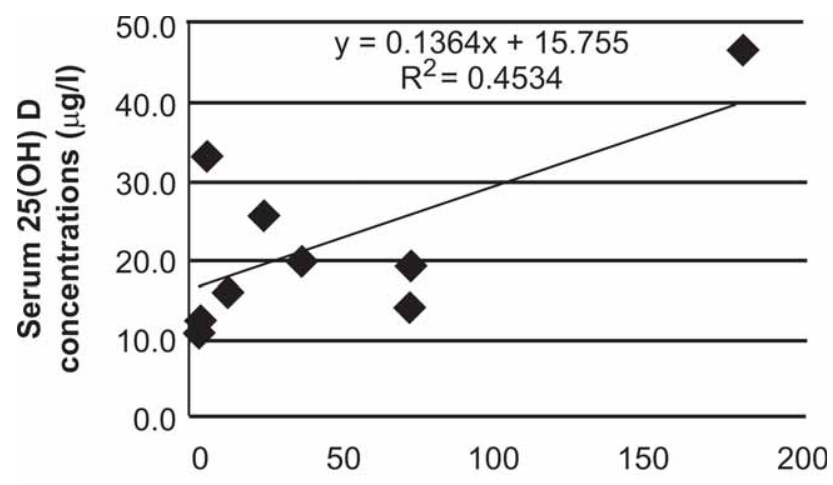

Duration of oral contraceptive use (months)

FIGURE 2. Correlation between serum vitamin D levels and oral contraceptive use duration

\section{REFERENCES}

1. Neurológia, $3^{\text {rd }}$ edition, Edited by Szirmai I. Medicina Könyvkiadó Zrt., Bp., 2011, pg. 419-427

2. Ascherio, Alberto, Kassandra L. Munger, K. Claire Simon. "Vitamin D and multiple sclerosis." The Lancet Neurology 9.6 (2010): 599-612.

3. Ascherio, Alberto, and Kassandra L. Munger. "Environmental risk factors for multiple sclerosis. Part II: Noninfectious factors." Annals of neurology 61.6 (2007): 504-513.

4. Thorogood, Margaret, Philip C. Hannaford. "The influence of oral contraceptives on the risk of multiple sclerosis." BJOG: An International Journal of Obstetrics \& Gynaecology 105.12 (1998): 1296-1299.
Based on our findings, cigarette smoking does not influence negatively the course of MS: no significant differences have been shown between the ARR and EDSS values or serum 25(OH) D levels of smokers and non-smokers. The results of other studies are characterized by heterogeneity and a trend towards smoking increasing the risk of transformation of relapsing-remitting SM to secondary progressive form (12). Smoking is furthermore considered as a risk factor and it is contra-indicated to all SM patients.

Oral contraceptive use is one of the few factors identified in our study that significantly increases vitamin D levels. Its benefic effect on disease progression is also possible, based on the lower ARR and EDSS scores of the OC user group. OC impact on calciferol concentrations is explained by estrogen increasing $\mathrm{D}$ vitamin binding protein (DBP) level (15). DBP is a vascular (and assumably intracellular) transport protein whose concentration is positively correlated to vitamin D metabolite levels (15). However, OC use was not associated with elevated free $1.25(\mathrm{OH})_{2}$ D levels, which is the only fraction available to excert metabolic effects in target cells (21). As a consequence, positive influence of OC use on vitamin D metabolic effects is still in question.

\section{Acknowledgments}

The authors thank the patients for participating in this study. We are grateful to Galenus Medical Center, for laboratory assistance with vitamin D assays. This study has been supported by Székely Forerunner Fellowship of Forerunner Federation.
5. Deluca, Hector F., Margherita T. Cantorna. "Vitamin D: its role and uses in immunology." The FASEB Journal 15.14 (2001): 2579-2585.

6. Correale, Jorge, María Célica Ysrraelit, María Inés Gaitán. "Immunomodulatory effects of Vitamin D in multiple sclerosis." Brain (2009): awp033.

7. Grau-López, Laia, et al. "Regulatory role of vitamin D in T-cell reactivity against myelin peptides in relapsing-remitting multiple sclerosis patients." BMC neurology 12.1 (2012): 103.

8. Simpson, Steve, et al. "Higher 25 -hydroxyvitamin $D$ is associated with lower relapse risk in multiple sclerosis." Annals of neurology 68.2 (2010): 193-203. 
9. Runia, Tessel F., et al. "Lower serum vitamin D levels are associated with a higher relapse risk in multiple sclerosis." Neurology 79.3 (2012): 261-266.

10. S. Smolders, Joost, et al. "Association of vitamin D metabolite levels with relapse rate and disability in multiple sclerosis." Multiple Sclerosis (2008).

11. El-Ghoneimy, Ahmed T., et al. "Contribution of vitamin D to the pathogenesis of multiple sclerosis and its effect on bone." Egyptian Journal of Neurology, Psychiatry and Neurosurgery 49 (2009): 209-222.

12. Wingerchuk, Dean M. "Smoking: effects on multiple sclerosis susceptibility and disease progression." Therapeutic advances in neurological disorders 5.1 (2012): 13-22.

13. Shirani, Afsaneh, Helen Tremlett. "The effect of smoking on the symptoms and progression of multiple sclerosis: a review." Journal of inflammation research 3 (2010): 115. (14) Harris, Susan S., and Bess Dawson-Hughes. "The association of oral contraceptive use with plasma 25-hydroxyvitamin D levels." Journal of the American College of Nutrition 17.3 (1998): 282-284.

14. Aarskog, Dagfinn, et al. "Effect of Estrogen on Vitamin D Metabolism in Tall Girls*." The Journal of Clinical Endocrinology \& Metabolism 57.6 (1983): 1155-1158.
15. Bolek-Berquist, Jilaine, et al. "Use of a questionnaire to assess vitamin D status in young adults." Public health nutrition 12.02 (2009): 236-243.

16. Kurtzke, John F. "Rating neurologic impairment in multiple sclerosis an expanded disability status scale (EDSS)." Neurology 33.11 (1983): 1444-1444.

17. Souberbielle, Jean-Claude, et al. "Vitamin D and musculoskeletal health, cardiovascular disease, autoimmunity and cancer: Recommendations for clinical practice." Autoimmunity reviews 9.11 (2010): 709-715.

18. Pierrot-Deseilligny, Charles, et al. "Relationship between 25-OH-D serum level and relapse rate in multiple sclerosis patients before and after vitamin D supplementation." Therapeutic advances in neurological disorders 5.4 (2012): 187-198.

19. Balasa, R. et al. Serum interleukin-10 levels in multiple sclerosis patients treated with IFN-B 1A. Acta Medica Transilvanica, 2014, 19(4)

20. Bouillon, Roger, et al. "Influence of the vitamin D-binding protein on the serum concentration of 1,25-dihydroxyvitamin D3: significance of the free 1, 25-dihydroxyvitamin D3 concentration." Journal of Clinical Investigation 67.3 (1981): 589. 